NBER WORKING PAPER SERIES

\title{
COMPETITION BETWEEN PRIVATE AND PUBLIC SCHOOLS: TESTING STRATIFICATION AND PRICING PREDICTIONS
}

\author{
Dennis Epple \\ David Figlio \\ Richard Romano \\ Working Paper 7956 \\ http://www.nber.org/papers/w7956 \\ NATIONAL BUREAU OF ECONOMIC RESEARCH \\ 1050 Massachusetts Avenue \\ Cambridge, MA 02138 \\ October 2000
}

Thanks to the U.S. Department of Education for providing the confidential data used in this project. The authors gratefully acknowledge financial support from the National Science Foundation under grants SBR9810615 (Figlio) and SBR-9601207 (Epple and Romano), and also the MacArthur Foundation. We also appreciate the comments of Eric Brunner, Genia Toma, Bill Sander, and conference participants at meetings of the American Economic Association, Southern Economic Association, and Association for Public Policy Analysis and Management, and the Federal Reserve Bank of Chicago. The views expressed in this paper are those of the authors and not necessarily those of the National Bureau of Economic Research.

(C) 2000 by Dennis Epple, David Figlio, and Richard Romano. All rights reserved. Short sections of text, not to exceed two paragraphs, may be quoted without explicit permission provided that full credit, including (C) notice, is given to the source. 
Competition Between Private and Public Schools:

Testing Stratification and Pricing Predictions

Dennis Epple, David Figlio, and Richard Romano

NBER Working Paper No. 7956

October 2000

JEL No. I21, I22, H72

\section{ABSTRACT}

When there are peer effects in education, private schools have an incentive to vary tuition to attract relatively able students. Epple and Romano (1998) develop a general equilibrium model characterizing equilibrium pricing and student selection into schools when peer effects are present. The model predicts that competition will lead private schools to give tuition discounts to more able students, and that this will give rise to an equilibrium exhibiting stratification by income and ability between the public and private sectors and to a hierarchy of schools within the private sector. The model also yields a variety of comparative-static predictions. The predictions of the model are tested in this paper using a unique data set assembled by Figlio and Stone (1999). Tests of equilibrium predictions of the model reveal that: The propensity to attend private school increases with both income and ability, and, among private schools, the propensity to attend the highest-tuition school rises with both income and ability. Within private schools, tuition declines with student ability, with a substantial of even high-income households paying little or no tuition. The correlation between income and ability is greater in public than private schools. Tests of comparative static predictions of the model reveal that: Both income and ability become stronger predictors of private school attendance as public school expenditure falls. Income becomes increasingly important in determining placement in the private school hierarchy as public school expenditure falls. Discounts to ability in the lowest-quality private school decline as public school expenditure rises while discounts to ability in the highest-quality private school are little affected by changes in public school expenditure. Expenditure in private schools rises as expenditure in public school increases. These empirical results are consistent with the predictions of the theoretical model.

Dennis Epple

Graduate School of Industrial Administration

Carnegie Mellon University

Posner Hall, Room 233 C

Pittsburgh, PA 15213

and NBER

epple@cmu.edu

Richard Romano

Department of Economics

University of Florida

Gainesville, FL 32611
David Figlio

Department of Economics

University of Florida

Gainesville, FL 32611

and NBER 


\title{
Competition Between Private and Public Schools: Testing Stratification and Pricing Predictions
}

\author{
Dennis Epple, David Figlio, and Richard Romano
}

1. Introduction. The United States is in the midst of an intensifying debate about the pros and cons of alternative educational reforms. Some proposed reforms, such as vouchers, entail changes to the current system that have thus far been implemented only on a relatively small scale. There is heated debate about the consequences of such reforms, were they to be adopted on a large scale. In this vein, a general equilibrium model to study educational policies was developed by Epple and Romano (1998a,1998b). ${ }^{1}$ Their model stresses household differences in income and student ability, the effects of own-ability and peer quality on educational achievement, and competition for students between and among public and private schools. Our objective in this paper is to test predictions of this model. A number of predictions about equilibrium stratification patterns, the school quality hierarchy, the distribution of educational benefits, and tuition structures of private schools are implied by the model. For example, tuition that declines with ability in private schools, including the possibility of fellowships for very high ability students, is predicted. Comparative static (and dynamic) implications of policy and parameter changes also emerge from the model. For example, policies that decrease public educational expenditure are predicted to not just increase private school patronage but also to decrease average per student expenditure among private schools. Tests of the stratification predictions of the model are of particular interest since stratification ("cream skimming" in more emotionally-charged parlance) is a central issue in debates about vouchers and other educational reforms.

Using a unique data set developed by Figlio and Stone (1999) and generated from the National Education Longitudinal Survey (NELS), the Schools and Staffing Surveys (SASS), and 
data collected by Dun and Bradstreet, this paper tests the central predictions of the Epple and Romano model. We find significant evidence that the stratification patterns predicted by the theoretical model are present in the data, and that the comparative-statics predictions of the model hold up across a battery of tests.

2. The Theoretical Model. A computational counterpart of the theoretical model has been developed to quantify theoretical predictions and, in some instances, to predict equilibrium outcomes when the general model fails to be definitive. Hence, both the general model and its calibrated counterpart are described here. The development that follows is less general and less detailed than in Epple and Romano (1998a,1998b).

A. Households, Preferences, and School Quality. Each household has exogenous income, y, and a student of exogenous ability, b. ${ }^{2}$ Households demand educational achievement for their child, where achievement is an increasing and differentiable function of student ability and school quality: $a=a(b, q)$, with q denoting school quality. School quality is an increasing, differentiable, and quasiconcave function of per student expenditure (in excess of "custodial costs" as discussed below), I, and peer student ability, $\theta: q=q(I, \theta)$. Peer student ability equals the mean ability in the school. ${ }^{3}$

Households pay a proportional income tax $\mathrm{t}$ to finance public education, and pay tuition $\mathrm{p}$ to attend school, with $\mathrm{p}=0$ if public school is attended. Letting $\mathrm{y}_{\mathrm{t}} \equiv \mathrm{y}(1-\mathrm{t})$ denote disposable income, utility is an increasing and differentiable function of numeraire consumption and achievement: $\mathrm{U}=\mathrm{U}\left(\mathrm{y}_{\mathrm{t}}-\mathrm{p}, \mathrm{a}\right)$. In what follows, we assume a Cobb-Douglas specification of utility, achievement, and school quality:

$$
\mathrm{U}=\left(\mathrm{y}_{\mathrm{t}}-\mathrm{p}_{\mathrm{i}}\right) \mathrm{b}_{\mathrm{i}}^{\beta} \mathrm{q}_{\mathrm{i}}^{\varsigma}=\left(\mathrm{y}_{\mathrm{t}}-\mathrm{p}_{\mathrm{i}}\right) \mathrm{b}_{\mathrm{i}}^{\beta} \mathrm{I}_{\mathrm{i}}^{\omega} \theta_{\mathrm{i}}^{\gamma}
$$

where the subscript $i$ is the number assigned to the school attended.

Observe that the utility function has the property that $\mathrm{U}_{\mathrm{q}} / \mathrm{U}_{\mathrm{y}}$ is increasing in $\mathrm{y}$, i.e., 
demand for school quality is everywhere a normal good. ${ }^{4}$ This assumption is key though uncontroversial. Note, too, that $\mathrm{U}_{\mathrm{q}} / \mathrm{U}_{\mathrm{y}}$ is invariant to $\mathrm{b}$. Our results also hold if demand for quality rises with student ability as is frequently assumed (see, e.g., Fernandez and Gali (1999)), but this is unnecessary.

The population density of student ability and household income is assumed continuous and positive on $\left[0, b_{x}\right] x\left[0, y_{x}\right]$ and denoted $f(b, y)$. Most of our results require no assumptions about the covariance of $(\mathrm{b}, \mathrm{y})$. In the computational analysis we assume a joint (truncated) lognormal distribution with zero or positive covariance.

Schooling. Every student will choose either a private or public school. Free public schooling is available to everyone and preferred to no schooling. Public and private schools have cost function:

$$
\mathrm{C}(\mathrm{k}, \mathrm{I})=\mathrm{F}+\mathrm{V}(\mathrm{k})+\mathrm{kI} ; \mathrm{V}^{\prime}, \mathrm{V}^{\prime \prime}>0
$$

where $\mathrm{k}$ is the number (mass) of students attending the school. The first two terms in the cost function consist of "custodial costs," and the third term expenditures on educational quality (e.g., more and/or more educated teachers). The specification implies a range of scale economies that is independent of school quality. Let $\mathrm{k}^{*}$ denote the efficient scale that then minimizes $[\mathrm{F}+\mathrm{V}(\mathrm{k})] / \mathrm{k}$.

Public schools are homogeneous in all respects. They have the same I, k, and peer measure. This conforms to a case of a single jurisdiction (i.e., school district) with one school or with frictionless choice across public schools (Epple and Romano (2000)). We note, however, that the assumption of a homogeneous public sector does not substantially affect the theoretical predictions of the model that we test. Ongoing work by Epple and Romano suggests that the nature of public-private selection and within-private-sector selection--the central features of the present paper--are qualitatively unchanged by introducing a heterogeneous public sector. Therefore, the assumption of a homogeneous public sector should not influence the empirical 
implications tested herein.

The value of $\mathrm{I}$ in the public sector is chosen by majority vote over the tax rate, while requiring a balanced government budget and the cost-minimizing integer number of public schools given equilibrium demand. Determination of voting equilibrium is discussed further below. Although equilibrium will have many public schools for realistic parameters, we will sometimes refer to "the" public school since public schools are homogeneous.

Private schools maximize profits as "utility takers," meaning they set tuition structure and choose quality taking as given households' equilibrium utilities. ${ }^{5}$ Private schools observe household income and student ability, and will then condition tuition on these attributes as optimal given competition from other schools. Free entry and exit of private schools is assumed. A private school's optimization problem and solution is developed below.

Equilibrium. Equilibrium satisfies household utility maximization, the presumed public-school policies, profit maximization by private schools, free entry and exit in the private sector, and a market-clearance condition. Households choose a school and vote for a tax rate to finance public education, taking as given other households' choices of schools, private-school tuitions and qualities, and the government's balanced-budget condition. Having households take privateschool characteristics as given is sensible since households are atomistic. Holding constant other households' school choices when voting and choosing a school is consistent with simultaneous choice by everyone of school and voting, or with sequential choice of school by everyone preceding voting. ${ }^{6}$ Note that households anticipate changes in public-school expenditure when voting through the balanced-budget condition, but holding fixed the aggregate public-private attendance pattern.

Profit maximization by private schools is, again, detailed below. The free entry and exit conditions is equivalent to requiring zero profits of all schools (given that incumbent schools maximize profits). Public-schooling policies have been discussed. Market clearance simply specifies that the measure of students of each type in the population equals the measure attending 
all existing schools.

Computational Model. Below we report some results from an extended version of the computational model in Epple and Romano (1998a). The computational model entails a choice of joint density function for income and ability, utility and achievement functions, and cost function for education. When possible we have calibrated the computational model to existing empirical evidence. We briefly summarize the Epple and Romano (1998a) calibration here and the changes made for this paper. In the latter paper we assumed all school quality variation is explained by variation in the peer group, while we here also let expenditures on educational inputs vary.

Income and ability follow a joint lognormal distribution: ${ }^{7}\left[\begin{array}{l}\operatorname{Ln}(b) \\ \operatorname{Ln}(y)\end{array}\right]$ is distributed bivariate normal with mean $\left[\begin{array}{l}\mu_{b} \\ \mu_{y}\end{array}\right]$ and covariance matrix $\left[\begin{array}{cc}\sigma_{b}^{2} & \rho \sigma_{b} \sigma_{y} \\ \rho \sigma_{b} \sigma_{y} & \sigma_{y}^{2}\end{array}\right]$. Calibrating the marginal distribution of income to mean $(\$ 36,250)$ and median $(\$ 28,906)$ income in 1989 yields $\mu_{\mathrm{y}}=3.36$ and $\sigma_{\mathrm{y}}=.68$ (with income measured in thousands).

To calibrate the distribution of ability, we assume that distribution to be a primitive, i.e., independent of policy changes. We further assume that annual future earnings while employed equal "normed achievement," where normed achievement is measured in the same units as ability, and both are measured in (future) dollars. As in Epple and Romano (1998), we choose initially an elasticity of achievement with respect to peer ability 20 percent as large as the elasticity with respect to own ability in the Cobb-Douglas achievement function (see (1)). This value is chosen somewhat conservatively to be two thirds the estimate obtained by Henderson, Mieszkowski, and Sauvageau (1977). Parameters for the ability distribution are then chosen to give rise to an approximate steady-state equilibrium with appropriate adjustment for the difference between ratios of employed workers per household and students per household. The outcome of this calibration process is $\mu_{\mathrm{b}}=2.51$ and $\sigma_{\mathrm{b}}=.58$.

Empirical evidence (Solon, 1992; Zimmerman, 1992) indicates that the correlation 
between father's income and son's income is approximately .4. This correlation is an upper bound on the correlation between father's income and son's ability in our model because the intergenerational correlation of income arises both from intergenerational correlation of ability and from the choice of higher-quality private schools by some higher-income households. Here we report results for the case of $\rho=.4$, but we have found surprisingly little difference in many predictions as $\rho$ declines to 0 . This completes the calibration of $f(b, y)$.

The Cobb-Douglas utility-achievement function implies zero ability elasticity of demand for school quality. The assumption that the effect of the peer group is not biased toward either high- or low-ability types seems an appropriate choice for a baseline model given the mixed empirical evidence about whether an improvement in peer group is more beneficial to high- or low-ability students. ${ }^{8}$

The share of disposable personal income spent on education in the U.S. in 1990 was approximately .056. Parameter $\gamma$ in (1) was chosen in Epple and Romano (1998a) to yield the observed expenditure share if school quality could be purchased at a constant price per unit of quality, implying $\gamma=.06$. Having here introduced variation in school inputs, we then assume $\omega+\gamma=.06$ and $\omega=\gamma$. The calibrated utility-achievement function is then:

$$
\mathrm{U}=\left(\mathrm{y}_{\mathrm{t}}-\mathrm{p}\right) \theta^{.03} \mathrm{I}^{.03} \mathrm{~b}^{.3}
$$

The cost function is $\mathrm{C}(\mathrm{k}, \mathrm{I})=12+(200+\mathrm{I}) \mathrm{k}+13,333.3 \mathrm{k}^{2}$, calibrated as follows. This function implies a cost-minimizing scale $\left(\mathrm{k}^{*}\right)$ of 3 percent of the population. It yields an equilibrium with public school expenditure per student of $\$ 4,200$ (or $\$ 2,100$ per household since we calibrate to $1 / 2$ student per household). This corresponds to observed U.S. expenditure per student in public school in our reference year (1990). This cost function implies a custodial cost per student of $\$ 2,000$ when schools operate at the efficient scale. In equilibrium, voters choose to spend an additional $\$ 2,200$ on inputs per public school student. This completes the calibration of the model.

3. Theoretical Results. A summary of theoretical implications of the model follows. We 
substitute intuitive discussion of the results for formal proofs, which can be found in Epple and Romano (1998a, 1998b).

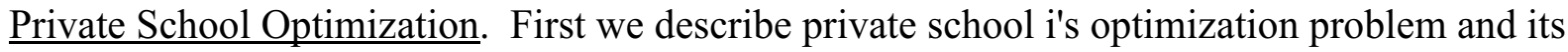
solution, $i \in\{1,2, \ldots, n\}$, where $n$ is the equilibrium number of private schools. Let $U_{i}{ }^{e}(b, y)$ denote the maximum utility type $(\mathrm{b}, \mathrm{y})$ can obtain by not attending school i. ${ }^{9}$ Let $\mathrm{p}_{\mathrm{i}}{ }^{*}\left(\mathrm{~b}, \mathrm{y}, \mathrm{q}_{\mathrm{i}}\right)$ satisfy denote type $(b, y)$ 's reservation price for attending school i. It satisfies: $U\left(y_{t}-p_{i}, a\left(q_{i}, b\right)\right)=U_{i}{ }^{e}(b, y)$. Profit maximization requires that school i charge admitted types their reservation price. Let $\alpha_{i}(b, y) \in[0,1]$ denote the admission function of school $\mathrm{i}$, which indicates the proportion of type $(b, y)$ in the population admitted to school i. Using these definitions, the optimization problem of school i may be written:

$$
\begin{gathered}
\text { MAX }\left\{\int_{0}^{\mathrm{y}_{\mathrm{x}} \mathrm{b}_{\mathrm{x}}} \mathrm{p}_{\mathrm{i}}^{*}\left(\mathrm{~b}, \mathrm{y}, \theta_{\mathrm{i}}^{\gamma} \mathrm{I}_{\mathrm{i}}^{\omega}\right) \alpha_{\mathrm{i}}(\mathrm{b}, \mathrm{y}) \mathrm{f}(\mathrm{b}, \mathrm{y}) \mathrm{dbdy}\right. \\
\left.-\mathrm{C}\left(\mathrm{k}_{\mathrm{i}}, \mathrm{I}_{\mathrm{i}}\right)\right\} \quad \text { over }\left[\alpha_{\mathrm{i}}(\cdot), \mathrm{I}_{\mathrm{i}}, \theta_{\mathrm{i}}, \mathrm{k}_{\mathrm{i}}\right] \\
\text { s.t. } \quad \alpha_{\mathrm{i}}(\mathrm{b}, \mathrm{y}) \in[0,1] \forall(\mathrm{b}, \mathrm{y}) ; \\
\mathrm{k}_{\mathrm{i}}=\int_{0}^{\mathrm{y}_{\mathrm{x}} \mathrm{b}_{\mathrm{x}}} \int_{0} \alpha_{\mathrm{i}}(\mathrm{b}, \mathrm{y}) \mathrm{f}(\mathrm{b}, \mathrm{y}) \mathrm{dbdy} ;
\end{gathered}
$$

and

$$
\theta_{\mathrm{i}}=\frac{1}{\mathrm{k}_{\mathrm{i}}} \int_{0}^{\mathrm{y}_{\mathrm{x}} \mathrm{b}_{\mathrm{x}}} \mathrm{b} \alpha_{\mathrm{i}}(\mathrm{b}, \mathrm{y}) \mathrm{f}(\mathrm{b}, \mathrm{y}) \mathrm{dbdy}
$$

where we have substituted the educational production function of school quality into the objective function.

The solution may be written:

$$
\alpha_{\mathrm{i}}(\mathrm{b}, \mathrm{y})\left(\begin{array}{c}
=1 \\
\in[0,1] \\
=0
\end{array}\right) \text { as } \mathrm{p}_{\mathrm{i}}{ }^{*}\left(\mathrm{~b}, \mathrm{y}, \mathrm{q}_{\mathrm{i}}\right)\left(\begin{array}{c}
> \\
= \\
<
\end{array}\right) \operatorname{EMC}_{\mathrm{i}}(\mathrm{b})
$$




$$
\begin{gathered}
\mathrm{EMC}_{\mathrm{i}}(\mathrm{b}) \equiv \mathrm{V}^{\prime}\left(\mathrm{k}_{\mathrm{i}}\right)+\eta_{\mathrm{i}}\left(\theta_{\mathrm{i}}-\mathrm{b}\right)+\mathrm{I}_{\mathrm{i}} \\
\eta_{\mathrm{i}}=\frac{1}{\mathrm{k}_{\mathrm{i}}} \int_{0}^{\mathrm{y}_{\mathrm{x}} \mathrm{b}_{\mathrm{x}}} \int_{0}^{\partial \mathrm{p}_{\mathrm{i}}^{*}\left(\mathrm{~b}, \mathrm{y}, \mathrm{q}_{\mathrm{i}}\right)} \frac{\partial \theta_{\mathrm{i}}}{\partial \mathrm{i}}(\mathrm{b}, \mathrm{y}) \mathrm{f}(\mathrm{b}, \mathrm{y}) \mathrm{dbdy} ;
\end{gathered}
$$

and

$$
\mathrm{k}_{\mathrm{i}}=\int_{0}^{\mathrm{y}_{\mathrm{x}} \mathrm{b}_{\mathrm{x}}} \int_{0}^{\partial \mathrm{p}_{\mathrm{i}}^{*}\left(\mathrm{~b}, \mathrm{y}, \mathrm{q}_{\mathrm{i}}\right)} \frac{\mathrm{I}_{\mathrm{i}}}{\partial \mathrm{i}}(\mathrm{b}, \mathrm{y}) \mathrm{f}(\mathrm{b}, \mathrm{y}) \mathrm{dbdy}
$$

To interpret the solution, first consider (5) which defines the "effective marginal cost (EMC)" of admitting student of ability $b$ into school $i$. This equals the marginal resource cost, $V^{\prime}+I_{i}$, plus the marginal cost of the peer-quality externality. The latter equals the change in $\theta_{\mathrm{i}}$ due to admitting student of ability $b$ (which equals $\left.\left(b-\theta_{i}\right) / k_{i}\right)$, multiplied by the negative of the implied adjustment to tuitions and thus revenues $\left(\eta_{\mathrm{i}} \mathrm{k}_{\mathrm{i}}\right.$; see (6)). Admitting a student with $\mathrm{b}<\theta_{\mathrm{i}}$ decreases school quality and necessitates tuition decreases. Admitting a student with $b>\theta_{i}$ increases school quality, permitting higher tuitions, with then a negative peer cost. Note that $\operatorname{EMC}_{\mathrm{i}}(\mathrm{b})<0$ is possible for sufficiently high-ability students. Condition (4) then indicates that the school admits all of the types whose reservation prices exceed their EMC, none of the types whose reservation prices are below their EMC, and is indifferent to admitting those whose reservation prices equal EMC. Condition (7) is the within school Samuelsonian condition determining optimal $\mathrm{I}_{\mathrm{i}}$. We should note that these conditions can be expressed in terms of the more primitive parameters of the utility function and characteristics of the school's student body (mean income and mean ability) using the Cobb-Douglas specification (1). This helps in deriving some of the equilibrium characteristics of the market to which we now turn.

Properties of Equilibrium. The analysis is complicated by an existence problem. The existence problem derives from the discreteness of schools (i.e., their fixed costs), is generic to club economies (see Scotchmer, 1994), and is manifest in an inability to have all private schools' 
profits exactly equal zero. Our resolution is to examine an "epsilon competitive equilibrium," that replaces the profit-maximization and zero-profit conditions on private schools with requirements that private schools are at local profit maxima (implying satisfaction of (3.1) - (7)), but allowing profit levels to differ from zero by a positive value $\epsilon$. Hence, entry (exit) will not occur unless $\pi_{i}>\epsilon \quad\left(\pi_{i}<-\epsilon\right)$ for some private school, nor would an incumbent school pursue non-local changes in admission/tuition policies unless it could gain more than $\epsilon$. The "equilibrium" results reported in the rest of the paper apply to our approximate equilibrium as well as exact equilibrium $(\epsilon=0)$ when it exists.

Next are reported a set of related equilibrium results, followed by some discussion of them. Some of the results are easily interpreted with reference to the computational examples depicted in Figure 1 (which is discussed further below). A subscript of 0 references a variable describing "the" public school. We refer to a locus in the (b,y)-plane that delineates the admission (or, equivalently, attendance) sets between schools $i$ and $j$ as a "boundary locus." These are the diagonal lines in the panels of Figure 1.

Result 1. A strict hierarchy of schools results with the public sector having the lowest-quality school: $\mathrm{q}_{\mathrm{n}}>\mathrm{q}_{\mathrm{n}-1}>\ldots>\mathrm{q}_{1}>\mathrm{q}_{0}$.

Result 2. a. Along a boundary locus between schools $i$ and $j, p_{i}=E C_{i}(b)$ and $p_{j}=E C_{j}(b)$ for any $i$ and/or $j \neq 0$ (i.e., for private schools). Private-school pricing on boundary loci is strictly according to ability.

b. $\mathrm{p}_{\mathrm{i}}(\mathrm{b}, \mathrm{y})>\mathrm{EMC}_{\mathrm{i}}(\mathrm{b})$ for $\mathrm{i} \neq 0$ in the interior of school i's admission space; private-school pricing off boundary loci also depends on income.

c. For given income, $p_{i}$ declines strictly in ability in schools $i=2,3, \ldots, n$ and weakly for $i=1$.

Result 3. a. Student choice of school is characterized by stratification by income meaning, for given ability, attendance at a higher-quality school implies strictly higher household income for 
almost every student (and weakly higher income for every student).

b. Student choice of schools satisfies stratification by ability, analogously defined.

Proofs of Results 1-3 are found in Epple and Romano (1998a, 1998b) while we provide intuition here. ${ }^{10}$ The strict hierarchy among private schools in Result 1 reflects the normality of demand for educational quality and the associated willingness of higher-income types to crosssubsidize higher-ability types to help create better schools. ${ }^{11}$ Even not allowing variation in per student expenditure, a strict hierarchy would obtain operating solely through the peer-group effect. This is likewise manifest in the discounting to ability of Results $2 \mathrm{a}$ and $2 \mathrm{c}$, and the stratification pattern in Result 3. The departure from EMC pricing in Result $2 \mathrm{~b}$ derives from some market power that private schools have due to their discrete sizes and discrete differences in quality. In our computational analysis, we have found the extent of price discrimination by income within schools to be severely limited by competition from other incumbent schools for students, with the exception of the very wealthy students in the top school. As Result 2c indicates, this competition for students leads tuition to decline with ability in any case.

The combination of income and ability stratification corresponds to the diagonal partition of student types illustrated by the examples in Figure 1. In each case depicted, the triangle with vertex at the origin comprises the set of students attending public school, and the remaining diagonal slices each comprise the attendance set of a private school. The upper-left panel depicts equilibrium with majority choice of per student public expenditure, and the remaining cases depict (so modified) equilibrium with exogenous and lower per student expenditure in the public sector. This variation in equilibria is motivate below, and the results reported here apply in all cases. The straight-line boundary loci are due to the Cobb-Douglas specification of (1). Another prediction concerns the size of private schools:

$\underline{\text { Result } 4}$. For equilibrium with $\epsilon$ sufficiently small, $\mathrm{k}_{\mathrm{i}}<\mathrm{k}^{*}, \mathrm{i}=1,2, \ldots, \mathrm{n}$. 
With free entry, $\epsilon$ will be small if the efficient scale, $\mathrm{k}^{*}$, is small. Then private schools will operate below the efficient scale. This is similar to the standard result that monopolistically competitive firms will operate below the scale where average cost is at a minimum.

We have also shown:

Result 5. a. $\mathrm{I}_{1}<\mathrm{I}_{2}<\ldots<\mathrm{I}_{\mathrm{n}}{ }^{12}$

b. However, $I_{0}$ can be greater than, equal to, or less than any $I_{i}, i=1,2, \ldots, n$.

Majority choice of per student expenditure in the public sector can lead to higher expenditure than in one or some private schools (Result 5b). Epple and Romano (1998b) have confirmed this possibility computationally. Private schools continue to provide higher quality education due to their higher-ability student bodies. Voting equilibrium exists as long as a majority attends a public school (so this is assumed). The Cobb-Douglas specification of preferences implies unanimity of preferences over tax-expenditure combinations among households that choose public schools. With public schools serving a majority, equilibrium then conforms to the preference of any public school patron, while households with children in private schools prefer a lower (minimal) tax rate. ${ }^{13}$

Ascension of the $\theta$ 's along the school quality hierarchy is also supported by the theory. This is implied by Result 1 when $\omega$ is sufficiently small, or if per student expenditure is not permitted to vary. Otherwise, we do not have formal proof that the $\theta$ 's must ascend except in special cases. ${ }^{14}$ Ability stratification will obviously tend to cause ascension of $\theta$ 's, however, and we find this consistently in our computational analysis. For example, the $\theta$ 's ascend in each case of Figure 1. We interpret our theory as predicting this ascension.

3. Empirical Evidence. The theoretical model described above predicts that students will be stratified by income and ability between the public and private sectors, as well as within the private sector, with the highest-ability and highest-income students in the top private school. 
This stratification pattern implies negative within-private-school relationships between income and ability, at least after controlling for positive correlation between income and ability in the population. Supporting the stratification pattern is the predicted negative relationship within private schools between tuition and ability. This section uses unique micro data to address whether these patterns are present in the data.

The Data. Because the model makes predictions about the distribution of individuals across schools, as well as about within-school differences in individual attributes, it is essential that the data used to test the model have several attributes: First, individual-level data are needed. While aggregate, school-level data could provide some sense as to the distribution of students across the public and private sectors, or even within the private sector, tests using only aggregate data cannot distinguish between the selection model implied by the theory and a simple story of individual tastes for schooling. Second, the data must be geographically identifiable, that is, it must be possible for the researcher to identify public and private schools in the same local markets. One reason that this second condition is necessary is that a credible study will rule out the possibility that there are geographically-correlated omitted variables. For instance, family incomes and the propensity to attend private schools are both higher in New England than in the Midwest, but this does not per se say anything about the stratification patterns within a specific educational market. Obviously, too, data from both competing public and private schools is needed to test the central predictions of the theory. A third requirement, though less important than the first two, is that the data should contain observations on a reasonably large number of students within the same school. This condition is important because it allows exploration of the within-school variation in the data, about which the theory has strong predictions. Fourth, a measure of individual ability in needed that is not an outcome of the school choice decision itself.

There exist no data in the public domain -- or even plausibly publicly-available restricted- 
use data -- that meet these criteria. However, we are able to utilize unique data that satisfy all four criteria. We use the restricted-use version of the National Education Longitudinal Survey (NELS), a nationally representative sample of public and private school students representing over one thousand schools, which first interviewed and tested eighth graders in 1988, then followed these students through high school and beyond. The restricted-use version of the NELS satisfies all but one of the criteria described above. First, the NELS is an individual-level data set, which is necessary as described above. Second, since the students are interviewed and tested at a relatively early age (relative to other longitudinal data sets), we have an initial measure of ability which is independent of the high school chosen. Third, the sampling design of the NELS is to first select schools, then sample multiple students in the same school, so we have multiple students in the same school. But while the restricted-access version of the NELS identifies the identities of its sampled public schools, it provides no meaningful geographical identifiers for its private schools. We were able to circumvent this problem, however, because we are able to use Figlio and Stone's (1999) matching of school-specific information reported in the NELS with data reported in a veritable census of private schools maintained by Dun and Bradstreet. This matching has allowed us to identify with certainty the sampled private schools, permitting us to use geographical information ideal for testing models like this, but not available in other data sets.

Our sample consists of 15,590 students in the NELS, with 1,952 of them enrolled in private schools. We are interested in predicting the sector attended by high school students, and conditional on being in the private sector, the specific private school that a student attends. Following the theory, our two individual-level variables of interest are ability and income. The NELS data report high-school sector for 20,190 students out of the 27,588 originally surveyed in the data, and of these, we only have eighth-grade test scores for 17,306 students. The remaining 1,716 omitted observations are missing parent-reported income data or are missing NCESassigned high school identification numbers which are necessary to identify the location and 
relative quality of the school that the student attends.

Parents of sampled students in the NELS report income data in fifteen categorical ranges, rather than as a continuous variable, so we use the range's midpoint as a proxy for the family income, reported in terms of 1988 dollars. (One percent of the observations have incomes in the top income range--over $\$ 200,000$. For these families we use $\$ 250,000$ as our measure of the family's income.) The mean income in the sample is $\$ 43,153$, with a standard deviation of $\$ 41,596$. There is considerable difference between the mean incomes in the public and private sectors, with the mean public-sector income equal to $\$ 36,900$, while the mean private-sector income is $\$ 86,844$.

Our proxy for ability is a student's eighth grade combined test score in mathematics and verbal ability. We contend that a student's eighth grade test score should be exogenous to the student's selection of a high school, so it is a reasonable proxy for the ability that the student brings into high school. ${ }^{15}$ The ability measure ranges from 27.4 to 110.6 points, with a mean of 63.7 and a standard deviation of 19.4. As with income, the raw data suggest a relationship between school sector and initial ability: public high school students have an average ability measure of 61.9 points, while private high school students average 76.7 points. It is important to note that neither mean ability nor mean income differs significantly between students included in our sample and those excluded because they are missing school sector, ability, or income measures.

Public-Private Selection. We begin by exploring stratification across the public and private sectors by ability and income, as described above. We estimate a simple logit regression model of sector selection ( $1=$ private sector; $0=$ public sector) on ability and income, and find, unsurprisingly, that both income and ability are strongly, independently related to sector choice, a central prediction of the theoretical model (see the first row of Table 1). Probit and linear probability models, the results of which are not reported herein, yield virtually identical results. 
Merely demonstrating these relationships in the data, however, does not guarantee that the stratification patterns predicted in the model truly exist. For instance, there could be some geographically determined third variable correlated with both income (or ability) and private school selection, so that within any given educational market there is really no stratification by income and ability. Though it is somewhat far-fetched to assume that this could be driving these results, a logical check on their validity of the results would involve conditioning on geography. The second and third sets of results reported in the first two columns of Table 1 report the results of conditional logit models, in which we in turn condition on metropolitan area (leaving us with 5,002 observations in the 61 metropolitan areas in which we observe sampled students enrolled in both public and private schools) or, alternatively, the county (leaving us with 3,423 observations in the 64 counties in which we observe sampled students enrolled in both public and private schools.) The benefit of these conditional logit models is that if the results remain, we can forcefully rule out the possibility that the stratification results are driven by some omitted geography-specific variable. We observe that the results are virtually unchanged in magnitude or statistical significance when we control for unobserved characteristics common to all students in a county or metropolitan area. Therefore, our first results provide evidence of cross-sector stratification by ability and income.

Within-Private-Sector Selection. The model predicts not only that high-ability, high-income students will differentially select into the private sector, but also that the private sector will be stratified by ability and income. Fortunately, our data permit us to directly address this question. Our strategy is to order the private schools in a metropolitan area (or county) according to their tuition charged, and to therefore identify a "top" private school, at least in terms in terms of the tuition charged. We use data from the Schools and Staffing Surveys and the Dun and Bradstreet data mentioned above to identify the top private school in each metropolitan area (or county). We then perform similar exercises to those reported in the preceding subsection. 
In this subsection, our dependent variable is a dichotomous variable indicating whether the student attends the private school with the highest average tuition in the metropolitan area (or county) in question. Result 5 purports that per student expenditure will be highest in the top school, and (near) zero profits then implies the highest average tuition there. ${ }^{16}$ If there is withinprivate sector stratification by income and ability, one would expect that the coefficients on income and ability would each be positive.

We report the results of these exercises in the second set of columns in Table 1. We observe that income and ability are each independently and strongly positively correlated with selection into the top private school in the metropolitan area (or county). We can combine these results and those reported above regarding public-private choice to generate predictions of whether each student will select into the public sector, the top private school, or a lower-tuition private school, and illustrate these predictions in ability-income space in Figure $2 .{ }^{17}$ The pattern of stratification, across and within-sectors, is apparent.

One can directly compute the slope of the boundary loci between the public and private sectors, or between the high-tuition and lower-tuition private schools, by evaluating the coefficients of the conditional logit models estimated above. Specifically, the slope of either boundary locus in income-ability space is merely $-\beta_{1} / \beta_{2}$, where $\beta_{1}$ is the coefficient on ability and $\beta_{2}$ is the coefficient on income in the logit models. ${ }^{18}$ The slopes of the boundary loci implied by the aforementioned models (conditioning on metropolitan area) are -2.31 (significantly different from zero at the $\mathrm{p}=0.000$ level) for the public-private boundary locus and -2.56 (significantly different from zero at the $\mathrm{p}=0.003$ level) for the within-private-sector boundary locus. The slopes of the boundary loci implied by the models conditioning on county are comparable in magnitudes and statistical significance. Therefore, these computations confirm what is visually apparent-that there exist significant stratification patterns consistent with those applied by the theory.

As an additional sensitivity check, we also restrict the sample to the set of private schools 
that are either the top or bottom-tuition private schools in the metropolitan area (or county), and estimate the probability of selecting into the top-tuition private school, conditional on being in either the top or bottom-tuition private school in the metropolitan area (or county). The results, reported in the third set of columns in Table 1, mirror those reported above. The slope of the boundary locus (in the specification conditioning on metropolitan area) between lowest-tuition and highest-tuition private school selection is estimated to be -2.9 , and significantly different from zero at the $\mathrm{p}=0.015$ level. (The slightly lower degree of significance is to be expected given the much smaller sample size in this specification.)

Finally, we estimate a multinomial logit model that allows us to simultaneously model selection into the public sector, the private lower-tuition sector, and the private top-tuition sector. The final set of columns in Table 1 presents the results of the multinomial logit specification in which the private school hierarchy is defined by the metropolitan area; therefore, students residing outside of metropolitan areas are omitted. The results, however, are very similar if we use the county as the basis of identification. We observe that the ability and income coefficients are stronger in the top-tuition private school selection equations than in the lower-tuition private school selection equations, a result consistent with the patterns of stratification across sectors and within the private sector observed above. While the multinomial logit models are in some ways less preferable because they do not control for metropolitan area (or county) specific fixed effects (as there exists no fixed-effects multinomial logit model), they are reassuring, in that the multinomial logit model predicts extremely similar stratification patterns to those found when we estimate the models sequentially as done above. Specifically, the multinomial logit model predicts boundary loci whose slopes are -1.92 for the public-private boundary and -2.33 for the within-private boundary. Both estimated slopes are significantly different from zero at the $\mathrm{p}=0.000$ level.

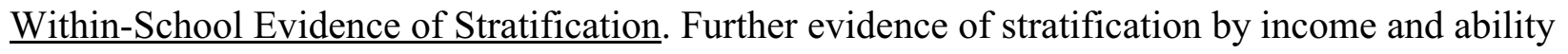


within the private sector can be found by looking within schools at the relationship between income and ability. The model predicts a negative relationship between income and ability within individual private schools, at least after controlling for positive correlation in the population between income and ability.

We explore this relationship by regressing ability on income, in a model that controls for school fixed effects. Any estimated coefficient for a model such as this is sure to be upwardbiased, relative to our model's predicted stratification properties, because of the strong positive correlation (0.35) between income and ability in the population. However, this bias will not affect the estimated differential relationship between income and ability observed in the public and private schools, which is, at its essence, what the model predicts. If the theoretical model is correct, one would expect a differentially negative within-school relationship in the private sector, relative to the public sector, because private schools are more stratified (e.g., see Figure 1). We observe in the first row of Table 2 that this is exactly what the data show. While the within-school relationship in the public sector is positive and strongly significant, the withinschool relationship in the private schools is negative, though statistically indistinguishable from zero. ${ }^{19}$ This statistical insignificance is unsurprising given the strong positive relationship between income and ability observed in the population. More to the point of testing the model's predictions, the relationships in the public and private sectors are significantly different from one another at any reasonable level of significance.

As an additional exercise, we now look within the private sector, to see whether there exist differences in this relationship between private, religious schools and private, nonreligious schools. The model is probably a more appropriate description of the private, nonreligious sector, given the possibility that private, religious schools have other motives than profitmaximization. Therefore, one might reasonably expect that, if anything, private, nonreligious schools should exhibit a stronger within-school income-ability relationship than will private, religious schools (though no difference between religious and nonreligious schools is wholly 
consistent with the theory if the two types of schools have similar motivations or if religious schools are largely constrained in their behavior by for-profit schools). We report the results of this exercise in the second set of columns in Table 2. We observe that while both the religious and nonreligious private sectors exhibit strong, negative within-school relationships between income and ability, there is substantial evidence suggesting that this result is stronger in the nonreligious private sector, consistent with our expectations. The difference between the religious and nonreligious sectors is statistically significant at the one percent level.

Discounting to Ability in the Private Sector. Table 2 also provides within-school evidence on the relationship between ability and tuition paid by students. We do not have a good measure of tuition paid by students in the NELS, but we can estimate tuition, to a first approximation, because parents report (in ranges) their "total education expenditures" expended in the current year. Therefore, for children without siblings, total education expenditure for the family will closely approximate total education expenditure for the child (assuming that parents are not also in school). While total education expenditure and tuition are different, they are surely highly related, and any mismeasurement should bias the relationship toward zero.

The second row of Table 2 reports the results of a school-fixed-effects regression of family education expenditure on ability and income, for the set of private school children without siblings in families with no reported current college expenditures. The coefficient on ability is negative and statistically significant, which is somewhat remarkable given the small sample size. (Recall that using reported household educational expenditures to infer tuition necessitates that we employ only households in the sample with one child leading to only 198 observations.) The coefficient on ability implies that a one-standard-deviation increase in ability leads to about a \$400 decrease in tuition paid, holding constant school fixed effects and family income. Given that the average of our tuition proxy is about $\$ 3000$, this suggests an elasticity of tuition with respect to ability of about one, when all variables are evaluated at their means. (The coefficient 
on income, not reported in the table, is positive and statistically significant, suggesting that private schools, on average, offer discounts to less wealthy students as well as discounts to ability.)

The evidence that private schools discount to ability is strengthened by the fact that thirty percent of families with incomes over $\$ 50,000$ (in 1990 dollars) and twenty percent of families with incomes over $\$ 75,000$ pay less than one-fifth of the stated maximum tuition of the schools they attend, and eighteen and thirteen percent, respectively, pay no tuition at all. Given that even custodial costs are surely higher than this amount, one can conclude that the granting of large tuition discounts to relatively wealthy families is an indication of discounting to ability. While none of these pieces of evidence are conclusive, they present a pattern suggestive of the abilitydiscounting predicted by the theory.

In sum, our results provide strong and consistent evidence supportive of the within-sector and cross-sector stratification patterns predicted by the theory.

Alternative Models. There are several alternative models that may have the potential to generate the findings reported above. Probably the most plausible of these alternative explanations is that we have omitted parental taste for education from our model. Taste for education could influence student ability (perhaps, for instance, due to past investment in the student) while also augmenting income in the demand for education. While taste for education is unmeasurable, we can at least proxy for parental taste for education with parental educational attainment. Our argument that taste for education is not driving our results would be strengthened if our results are robust to inclusion of parental education levels in the empirical model.

To determine whether this is the case, we augment the models described in Table 1 with a series of controls for whether the student's most-educated parent is a high school graduate, a college graduate, or a graduate/professional degree holder (according to parental reports.) The results of this exercise suggest that our results are not substantially affected by proxies for parental tastes. For ease of exposition, we discuss the results of regressions analogous to those 
reported in the second row of Table 1 (conditional logit models, conditioning on metropolitan area of residence.) Consider the first set of results (explaining the public-private choice.) The coefficient on ability falls moderately to 0.021 (with a standard error of 0.002 ) from 0.030 , and the coefficient on income falls slightly from 0.013 to 0.011 (with a standard error of 0.001 .) With regard to the second set of results (explaining the probability that a private school student is enrolled in the high-tuition school in the metropolitan area,) the coefficient on ability falls moderately from 0.023 to 0.017 (with a standard error of 0.006 ) and the coefficient on income falls somewhat from 0.009 to 0.006 (with a standard error of 0.002.) Finally, with respect to the third set of results (explaining the probability that a private school student is enrolled in the hightuition school, rather than the low-tuition school, in the metropolitan area,) the coefficient on ability falls somewhat from 0.029 to 0.023 (with a standard error of 0.009 ) and the coefficient on income falls moderately from 0.010 to 0.007 (with a standard error of 0.003.) In sum, accounting for a proxy for parental tastes, while they surely affect school choice, does not dramatically effect our estimated relationships presented in Table 1. Thus, it is unlikely that our results can be explained away by omitted parental tastes for education.

One might be concerned that our findings about ability stratification are driven by demand for educational quality rising with student ability. However, this explanation is inconsistent with the evidence that there exists considerable discounting to ability in the private sector, since the alternative explanation would suggest that the reverse would hold in the top private school, with a near-zero effect in other private schools. ${ }^{20}$ A third, but related, concern might be that our measured discounting to ability merely reflects lower resource costs associated with educating higher-ability students. But this explanation would still imply that high-ability students should at least pay some positive tuition; however, as noted above, a significant proportion of high-income families pay zero or near-zero private school tuition. Therefore, none of these alternative explanations are supported in the data. 
4. Comparative Statics. Comparative-static predictions provide another means to test the theory. Here we consider exogenous changes in per student public-sector expenditure as one possible comparative statics exercise. This is motivated by the observed large variation across school districts in per student expenditure, much of which can be attributed to differences in state-level policies and their differential effects at the local level. These policies include, for instance, property-tax limitations (Figlio (1997), Figlio and O'Sullivan (forthcoming)) and court-mandated school finance reforms (Murray, Evans and Schwab, 1998), which can be treated as exogenous to the current stratification patterns observed ten to fifteen years following their imposition.

Theoretical Predictions. We modify our theoretical model by treating per student public expenditure as exogenous, and examine computationally the effects of varying it. The upper-left panel of Figure 1 depicts the equilibrium allocation in the benchmark case where per student expenditure in the public sector is determined by majority vote. This leads to a public sector attended by 94 percent of the population and three private schools serving the remaining students. The three other panels of Figure 1 depict the equilibrium allocations with progressively lower levels of per student expenditure in the public sector.

Figure 1 makes clear that decreased public-school expenditure per student will lead to entry of private schools and a contraction of the public sector. Figure 3 shows the percentage of public sector attendance as a function of per student expenditure in the public sector. One can also see that students with income and/or ability that is relatively high (low) compared to other public- (private-)school students will be those that switch sectors. Hence, income and ability should become stronger predictors of private-school attendance as per student expenditure in the public sector declines.

Somewhat more subtle are effects on the relative importance of income and ability as predictors of private school attendance and placement in the hierarchy of private schools. While both income and ability should become stronger predictors of private-school attendance as the 
public sector contracts due to lower per student expenditure there, income becomes relatively more important than ability in predicting placement in the hierarchy of schools: Boundary loci become flatter in the $(\mathrm{b}, \mathrm{y})$ plane. This is apparent in Figure 1. At the bottom end of the privateschool hierarchy, discounts to ability decline as the marginal school serves a poorer population, i.e., $\eta_{1}$ declines looking across equilibria with lower per student public-sector expenditure as shown in Figure 4. ${ }^{21}$ This implies that fewer relatively poor and relatively high-ability students are drawn into the marginal private school. While discounts to ability in initial private schools rise when new schools enter, differences in discounts to ability among preexisting private schools decline as competition for high-ability students intensifies. ${ }^{22}$ This leads top schools to substitute lower-ability, higher-income students for higher-ability, lower-income students to some degree. As Figure 1 depicts, boundary loci generally become flatter with private school entry, but this is more pronounced at the lower end of the hierarchy.

Empirical Evidence. We can augment our dataset with public school expenditure data from the Census of Governments to test the comparative-statics predictions described above. Table 3 presents evidence of the changes in cross-sector and within-sector selection by ability and income as public school expenditure in the metropolitan area changes.

Let us first consider the relationship between local public school expenditures and the public-private boundary locus. To address this question, we estimate a conditional logit model (conditioning on metropolitan area) that is identical to the conditional logit models presented in Table 1, except that we also interact ability and income with per pupil public school expenditures in the metropolitan area. We then use the parameters estimated from this model to gauge important attributes of the location of the boundary locus.

First, consider the slope of the public-private boundary locus. The theoretical model predicts that as local public per pupil expenditure falls, the boundary locus between the public and private sectors should become flatter (that is, less negatively sloped.) The slope of the 
public-private boundary locus in income-ability space is:

$$
\frac{\partial y}{\partial b}=\frac{-\left(\alpha_{1}+\alpha_{2} I_{p}\right)}{\alpha_{3}+\alpha_{4} I_{p}}
$$

where $I_{p}$ reflects local public school spending; $\alpha_{1}$ is the coefficient on ability; $\alpha_{2}$ is the coefficient on ability interacted with local public per-pupil spending; $\alpha_{3}$ is the coefficient on income; and $\alpha_{4}$ is the coefficient on income interacted with local public per-pupil spending. The comparativestatics prediction that the boundary locus flattens as public expenditures fall can therefore be tested by:

$$
\operatorname{sign}\left[\frac{\partial^{2} y}{\partial b \partial I_{p}}\right]=\operatorname{sign}\left[\alpha_{1} \alpha_{4}-\alpha_{2} \alpha_{3}\right]
$$

From the parameter estimates reported in the first column of Table 3 this term is negative (-.0003), and the nonlinear combination of parameters is statistically significant at the $p=0.000$ level. Therefore, the results suggest that as expenditures decrease, the slope of the public-private boundary locus becomes flatter, as the theory predicts.

The theory also has predictions for the shifting in the public-private boundary locus. Specifically, the model implies that, along this locus:

$$
\frac{\partial y}{\partial \mathrm{I}_{\mathrm{p}}}=\frac{-\alpha_{\mathrm{I}}-\alpha_{4} \mathrm{y}-\alpha_{2} \mathrm{~b}}{\alpha_{3}+\alpha_{4} \mathrm{I}_{\mathrm{p}}}>0, \frac{\partial \mathrm{b}}{\partial \mathrm{I}_{\mathrm{p}}}=\frac{-\alpha_{\mathrm{I}}-\alpha_{4} \mathrm{y}-\alpha_{2} \mathrm{~b}}{\alpha_{3}+\alpha_{2} \mathrm{I}_{\mathrm{p}}}>0
$$

where $\alpha_{I}$ is the implied coefficient on per-pupil spending. This parameter is not directly estimated in the conditional logit model because the model already implicitly controls for all variables (including public school expenditures) that are common to every observation in a metropolitan area. However, there exists considerable evidence (e.g., Long and Toma, 1988) to suggest that $\alpha_{I}<0$, and in fact, we also find this relationship in our data when we estimate 
unconditional logit models. Therefore, we conclude that the assumption that private school attendance decreases with public school spending is a reasonable one to make. The first condition in (10) implies that as public school spending decreases, the boundary locus shifts toward including lower-income students in the private sector, and the second condition implies that as public school spending decreases, the boundary locus shifts toward including lowerability students in the private sector. Evaluating income, ability, and per-pupil expenditures at their means, and using the estimated parameters from the first column of Table 3 , we observe that the denominators of both expressions are positive, and the numerators, even before including the $-\alpha_{\text {I }}$ portion, are both positive as well. Since $\alpha_{\mathrm{I}}$ is almost surely negative, this portion would just reinforce the positive sign of the conditions. Since we cannot estimate $\alpha_{\mathrm{I}}$, we cannot determine the significance level of the signs of these conditions. However, even before considering the $\alpha_{\text {I }}$ portion, these expressions are significant at around the 12 percent level when evaluating all variables at their means. ${ }^{23}$ Therefore, these results provide some additional evidence supporting the theoretical model.

Of course, there remains the possibility that an omitted variable correlated with per pupil public school expenditure is driving our results. To gauge whether this makes a difference, we augment the previously-reported specification with interactions between income and ability and several other local covariates reflecting community income, race, and education levels. Specifically, we interact ability and income with, in turn, the median income, percentage nonwhite, and percentage of adults with bachelors degrees, in the metropolitan area. None of these additional covariates substantively affects the results described above. Thus, this provides some additional evidence that our results are robust. ${ }^{24}$

The model suggests that the slope of the high-tuition boundary locus should be less affected by changes in local expenditures than is the slope of the public-private boundary locus. To address this possibility, we report in the second column of Table 3 an analogous model to that reported above, but instead looking at the top-versus-low-tuition private school boundary. We 
calculate that the estimated effect of public school spending on the slope of the within-private locus is less than half the effect on the public-private locus, and that the estimated effect on the within-private locus is not significant at traditional levels, all as predicted by the model.

The theoretical model also predicts that per student private school expenditure across all private schools should increase with public school expenditures. The dominant effect here is the exit of low-expenditure private schools due to increased public expenditure. This prediction is borne out in the data (though not reported in tables in the present paper.) For every $\$ 1000$ increase in county public school expenditures, private school tuitions average $\$ 612$ increases, a result that is statistically distinct from zero at any reasonable significance threshold. ${ }^{25}$

Finally, while we have insufficient data to explore differences in the within-school tuition-ability relationship, we can at least explore the effects of changing public expenditures on the within-school income-ability relationship. Table 4 provides evidence on how the incomeability relationship within private schools changes as public school expenditures change. Our computational model predicts that as public expenditures fall, the within private school relationship between income and ability should decrease in magnitude for marginal private schools, but is unexpected to change appreciably for top private schools in an area. This corresponds to the flattening of boundary loci of private-school entrants as public expenditure declines that can be seen in Figure 1.

To test this presumption, we stratify private schools on the basis of tuition and observe how the within-school income-ability relationship varies with public school expenditure in toptuition and low-tuition private schools. The predictions are borne out in the data: we observe no relationship between public school expenditures and the within-school income-ability relationship in top private schools. However, this relationship is as predicted in the lowesttuition private schools: the negative interaction term is modestly statistically significant at about the seven percent level. This negative interaction coefficient for lower-tuition private schools suggests that the ability-income relationship within marginal schools flattens as public spending 
falls, a result consistent with the theory. ${ }^{26}$ Therefore, all of our empirical evidence supports the comparative-static predictions of the theory.

5. Summary and Conclusion. We have tested a variety of equilibrium and comparative static predictions of the theoretical model. Testing equilibrium predictions of the model, we find: The propensity to attend private school increases with both income and ability, and, among private schools, the propensity to attend the highest-tuition school rises with both income and ability. Within private schools, tuition declines with student ability, with a substantial fraction of even high-income households paying little or no tuition. The correlation between income and ability is greater in public than private schools consistent with predicted private school pricing. Testing comparative-static predictions of the model we find: Both income and ability become stronger predictors of private school attendance as public school expenditure falls. Income becomes increasingly important in determining placement in the private school hierarchy as public school expenditure falls. Discounts to ability in the lowest-quality private school decline as public expenditure rises while discounts to ability in the highest-quality private school are little affected by changes in public school expenditure. Expenditure in private schools rises as expenditure in public school increases. These empirical results are consistent with the theoretical model described above. There is thus considerable evidence in the data that students are stratified by income and ability across sectors and within the private sector as the model predicts, and evidence that these patterns are an outcome of competition-induced pricing by private schools aimed at attracting more able students. Moreover, the evidence supports the notion that stratification patterns change with public school expenditures in the manner predicted by the model. The results lend credibility to the use of this theoretical set up to explore the effects of educational policies such as educational vouchers and centralized financing on the distribution of students across and within sectors, as well as on the distribution of student outcomes. The results also suggest the importance of giving attention to "cream skimming" issues in educational policy formation like voucher design. 
$\underline{\text { References. }}$

Arnott, Richard and John Rowse, "Peer Group Effects and Educational Attainment," Journal of Public Economics, April 1987, 32(3), 287-305.

Benabou, Roland, "Equity and Efficiency in Human Capital Investment: The Local Connection,"

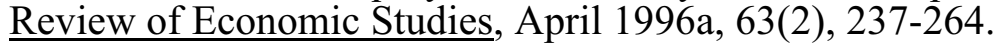

, "Heterogeneity, Stratification, and Growth: Macroeconomic Implications of Community Structure and School Finance," American Economic Review, June 1996b, 86(3), 584-609.

Black, Sandra E., "Do Better Schools Matter? Parental Valuation of Elementary Education," Quarterly Journal of Economics, May 1999, 114(2), 577-600.

Caucutt, Elizabeth, "Educational Vouchers When There Are Peer Group Effects -- Size Matters," International Economic Review, forthcoming.

Conley, John and Myrna Wooders,"Hedonic Independence and Taste-Homogeneity of Optimal Jurisdictions in a Tiebout Economy with Crowding Types," University of Illinois, February 1998.

de Bartolome, Charles A.M., "Equilibrium and Inefficiency in a Community Model with Peer Group Effects," Journal of Political Economy, February 1990, 98(1), 110-133.

Epple, Dennis and Richard Romano, "Ends Against the Middle: Determining Public Service Provision When There Are Private Alternatives," Journal of Public Economics, November 1996, 62(3), 297-325.

, "Competition Between Private and Public Schools, Vouchers, and Peer-Group Effects, American Economic Review, March 1998a, 88(1), 33-62. , "Educational Vouchers and Cream Skimming," 1998b.

"Neighborhood Schools, Choice, and the Distribution of Educational Benefits," University of Florida, July 2000.

Fernandez, Raquel and Jordi Gali, "To Each According To...? Markets, Tournaments, and the Matching Problem with Borrowing Constraints," Review of Economic Studies, October 1999, 799-825.

Figlio, David, "Did the 'Tax Revolt' Reduce School Performance?” Journal of Public Economics, September 1997, 245-269.

and Arthur O’Sullivan, “Do Local Governments Manipulate Voters to Increase Revenues?" Journal of Law and Economics, forthcoming. and Joe Stone, “Are Private Schools Really Better?" Research in Labor Economics, Solomon Polachek, ed., 1999, 115-140.

Gans, J.S. and M. Smart, "Majority Voting With Single-Crossing Preferences," Journal of Public Economics, 1996, 59, 219-237. 
Henderson, Vernon, Peter Mieszkowski, and Yvon Sauvageau, "Peer Group Effects in Educational Production Functions," Journal of Public Economics, August 1978, 10(1), 97-106.

Long, James and Eugenia Toma, "The Determinants of Private School Attendance, 1970-1980," Review of Economics and Statistics, 70(2), May 1988, 351-357.

Murray, Sheila, William Evans and Robert Schwab, "Education Finance Reform and the Distribution of Education Resources," American Economic Review, 88(4), 1998, 789-812.

Nechyba, Thomas, "School Finance Induced Migration and Stratification Patterns: The Impact of Private School Vouchers," Journal of Public Economic Theory, 1(1), 1999, 5-50. Review, 90(1), 2000, 130-146.

Rothschilde, Michael and Lawrence White, "The Analytics of the Pricing of Higher Education and Other Services in Which the Customers Are Inputs," Journal of Political Economy," June $1995,103(3), 573-623$.

Scotchmer, Suzanne, "Public Goods and the Invisible Hand," in J. Quigley and E. Smolensky, eds., Modern Public Finance, Cambridge, MA: Harvard University Press, 1994, 98-119.

Solon, Gary, "Intergenerational Income Mobility in the United States," American Economic Review, June 1992, 82(3), 393-409.

Summers, Anita A. and Barbara L. Wolfe, "Do Schools Make a Difference?" Anerican Economic Review, September 1977, 67(4), 639-52.

Zimmer, Ron and Eugenia Toma, "Peer Effects and Public Schools Across Countries," Journal of Policy Analysis and Management, 1999,

Zimmerman, David, "Regression Toward Mediocrity in Economic Stature," American Economic Review, June 1992, 82(3), 409-29. 
Table 1: Evidence on Cross-School Stratification by Ability and Income

\begin{tabular}{|c|c|c|c|c|c|c|c|c|c|c|}
\hline & (1a) & (1b) & (2a) & (2b) & $(3 a)$ & (3b) & (4a) & (4b) & $(4 c)$ & $(4 d)$ \\
\hline & $\begin{array}{l}\text { Logit mo } \\
\text { privates }\end{array}$ & $\begin{array}{l}\text { probability of } \\
\text { l selection }\end{array}$ & $\begin{array}{l}\text { Logit mo } \\
\text { of select } \\
\text { private s }\end{array}$ & $\begin{array}{l}\text { probability } \\
\text { high tuition } \\
\text { ol }\end{array}$ & $\begin{array}{l}\text { Logit mo } \\
\text { selectin } \\
\text { private }\end{array}$ & $\begin{array}{l}\text { probability of } \\
\text { tuition } \\
l^{\dagger}\end{array}$ & $\begin{array}{l}\text { Multinomial l } \\
\text { private, and } t \\
\text { (conditional o }\end{array}$ & $\begin{array}{l}\text { git model: } s \\
\text {-tuition pri } \\
\text { being in } \mathrm{me}\end{array}$ & $\begin{array}{l}\text { ion amon } \\
\text { schools } \\
\text { area) }\end{array}$ & lic, low-tuition \\
\hline & & & & & & & $\begin{array}{l}\text { Low-tuition } \mathrm{p} \\
\text { selection equa }\end{array}$ & $\begin{array}{l}\text { vate school } \\
\text { on }\end{array}$ & $\begin{array}{l}\text { Top-tuit } \\
\text { selectior }\end{array}$ & $\begin{array}{l}\text { ivate school } \\
\text { tion }\end{array}$ \\
\hline $\begin{array}{l}\text { Variable (column) } \\
\text { Specification (row) }\end{array}$ & $\begin{array}{l}\text { Ability } \\
\text { coeff. }\end{array}$ & $\begin{array}{l}\text { Income } \\
\text { coeff. }^{+\dagger \dagger}\end{array}$ & $\begin{array}{l}\text { Ability } \\
\text { coeff. }\end{array}$ & $\begin{array}{l}\text { Income } \\
\text { coeff. }\end{array}$ & $\begin{array}{l}\text { Ability } \\
\text { coeff. }\end{array}$ & $\begin{array}{l}\text { Income } \\
\text { coeff. }\end{array}$ & Ability coeff. & $\begin{array}{l}\text { Income } \\
\text { coeff. }\end{array}$ & $\begin{array}{l}\text { Ability } \\
\text { coeff. }\end{array}$ & Income coeff. \\
\hline $\begin{array}{l}\text { Specification with no fixed } \\
\text { effects }\end{array}$ & $\begin{array}{c}0.027 \\
(0.001)\end{array}$ & $\begin{array}{c}0.017 \\
(0.001)\end{array}$ & $\begin{array}{l}0.017 \\
(0.004)\end{array}$ & $\begin{array}{l}0.006 \\
(0.001)\end{array}$ & $\begin{array}{l}0.020 \\
(0.006)\end{array}$ & $\begin{array}{c}0.007 \\
(0.002)\end{array}$ & $\begin{array}{l}0.025 \\
(0.002)\end{array}$ & $\begin{array}{l}0.013 \\
(0.001)\end{array}$ & $\begin{array}{l}0.042 \\
(0.004)\end{array}$ & $\begin{array}{c}0.018 \\
(0.001)\end{array}$ \\
\hline Observations & 15590 & & 1281 & & 511 & & 9470 & & & \\
\hline $\begin{array}{l}\text { Conditional logit: } \\
\text { conditioning on metropolitan } \\
\text { area }^{\dagger \dagger \dagger \dagger}\end{array}$ & $\begin{array}{c}0.030 \\
(0.002)\end{array}$ & $\begin{array}{c}0.013 \\
(0.001)\end{array}$ & $\begin{array}{c}0.023 \\
(0.006)\end{array}$ & $\begin{array}{c}0.009 \\
(0.002)\end{array}$ & $\begin{array}{c}0.029 \\
(0.009)\end{array}$ & $\begin{array}{l}0.010 \\
(0.003)\end{array}$ & $\mathrm{n} / \mathrm{a}$ & & $\mathrm{n} / \mathrm{a}$ & \\
\hline Observations & 5002 & & 661 & & 375 & & & & & \\
\hline Observations & 3423 & & 516 & & 229 & & & & & \\
\hline
\end{tabular}

Notes: Standard errors are in parentheses beneath coefficient estimates.

$\dagger$ : Sample is the set of students enrolled in private schools.

$\dagger \uparrow$ : Sample is the set of students enrolled in either the top-tuition or bottom-tuition private school in a metropolitan area (or county in the bottom column).

$\dagger \dagger \dagger:$ Income expressed in thousands of 1988 dollars throughout table.

$+\dagger \dagger \dagger$ : Sample is the set of metropolitan areas with both public and private schools sampled (or in the second and third sets of columns, both types of private schools sampled.)

$+\dagger+\dagger$ : Sample is the set of counties with both public and private schools sampled (or in the second and third sets of columns, both types of private schools sampled.) 
Table 2: Evidence of Within-School Income-Ability and Tuition-Ability Relationship ${ }^{\dagger \dagger}$

\begin{tabular}{|c|c|c|c|c|c|c|}
\hline & (1a) & (2) & (3) & (4) & (5) & (6) \\
\hline & Public schools & Private schools & $\begin{array}{l}\text { Difference } \\
\text { between private } \\
\text { and public }\end{array}$ & $\begin{array}{l}\text { Religious private } \\
\text { schools } \\
\text { (relative to } \\
\text { public) }\end{array}$ & $\begin{array}{l}\text { Nonreligious } \\
\text { private schools } \\
\text { (relative to } \\
\text { public) }\end{array}$ & $\begin{array}{l}\text { Difference between } \\
\text { nonreligious and } \\
\text { religious private }\end{array}$ \\
\hline $\begin{array}{l}\text { Within-school relationship between } \\
\text { income and ability (school fixed } \\
\text { effects) }\end{array}$ & $\begin{array}{c}0.282 \\
(0.018)\end{array}$ & $\begin{array}{l}-0.058 \\
(0.056)\end{array}$ & $\begin{array}{l}-0.340 \\
(0.058)\end{array}$ & $\begin{array}{l}-0.234 \\
(0.071)\end{array}$ & $\begin{array}{l}-0.544 \\
(0.097)\end{array}$ & $\begin{array}{l}-0.310 \\
(0.117)\end{array}$ \\
\hline $\begin{array}{l}\text { Within-school relationship between } \\
\text { proxied tuition }{ }^{\dagger} \text { and ability (school } \\
\text { fixed effects) }\end{array}$ & $\mathrm{n} / \mathrm{a}$ & $\begin{array}{l}-0.0013 \\
(0.0004)\end{array}$ & $\mathrm{n} / \mathrm{a}$ & $\mathrm{n} / \mathrm{a}$ & $\mathrm{n} / \mathrm{a}$ & $\mathrm{n} / \mathrm{a}$ \\
\hline
\end{tabular}


Table 3: Public School Expenditures and

Cross-Sector Stratification by Ability and Income

(Conditional logit models of probability of private school selection, conditioning on metropolitan area):

$\begin{array}{lll} & \begin{array}{l}\text { Conditional Logit model: } \\ \text { probability of private } \\ \text { school selection }\end{array} & \begin{array}{l}\text { Conditiona } \\ \text { tuition p }\end{array} \\ \text { Coefficient } & 0.020 & \\ \text { Ability } & (0.006) & -0.087 \\ & 0.002 & (0.057) \\ \text { Ability x public school } & (0.001) & 0.018 \\ \text { expenditure (1000s) } & 0.028 & (0.010) \\ \text { Income (1000s) } & (0.003) & -0.015 \\ & -0.003 & (0.014) \\ \text { Income x public school } & (0.001) & 0.004 \\ \text { expenditure (1000s) } & & (0.002)\end{array}$

Notes: Standard errors are in parentheses beneath coefficient estimates. The models also implicitly control for MSAlevel per pupil expenditures in the public sector, though this parameter is not estimated in the MSA-conditioned conditional logit model. 
Table 4: Public School Expenditures and the Within-School Income-Ability Relationship:

Fixed Effects Models; Dependent variable: Ability

$\begin{array}{lll}\text { Sample } & \begin{array}{l}\text { Income } \\ \text { coeff. }\end{array} & \begin{array}{l}\text { Income x per pupil expenditure } \\ (1000 \mathrm{~s}) \text { coefficient }\end{array} \\ \text { Top tuition private schools } & -0.017 & 0.001 \\ & (0.071) & (0.011) \\ \text { Lowest tuition private schools } & 0.162 & -0.038 \\ & (0.109) & (0.021)\end{array}$

Notes: Standard errors are in parentheses beneath coefficient estimates. 
FIGURE 1

ADMISSION SPACES FOR FOUR PUBLIC SCHOOL EXPENDITURE LEVELS
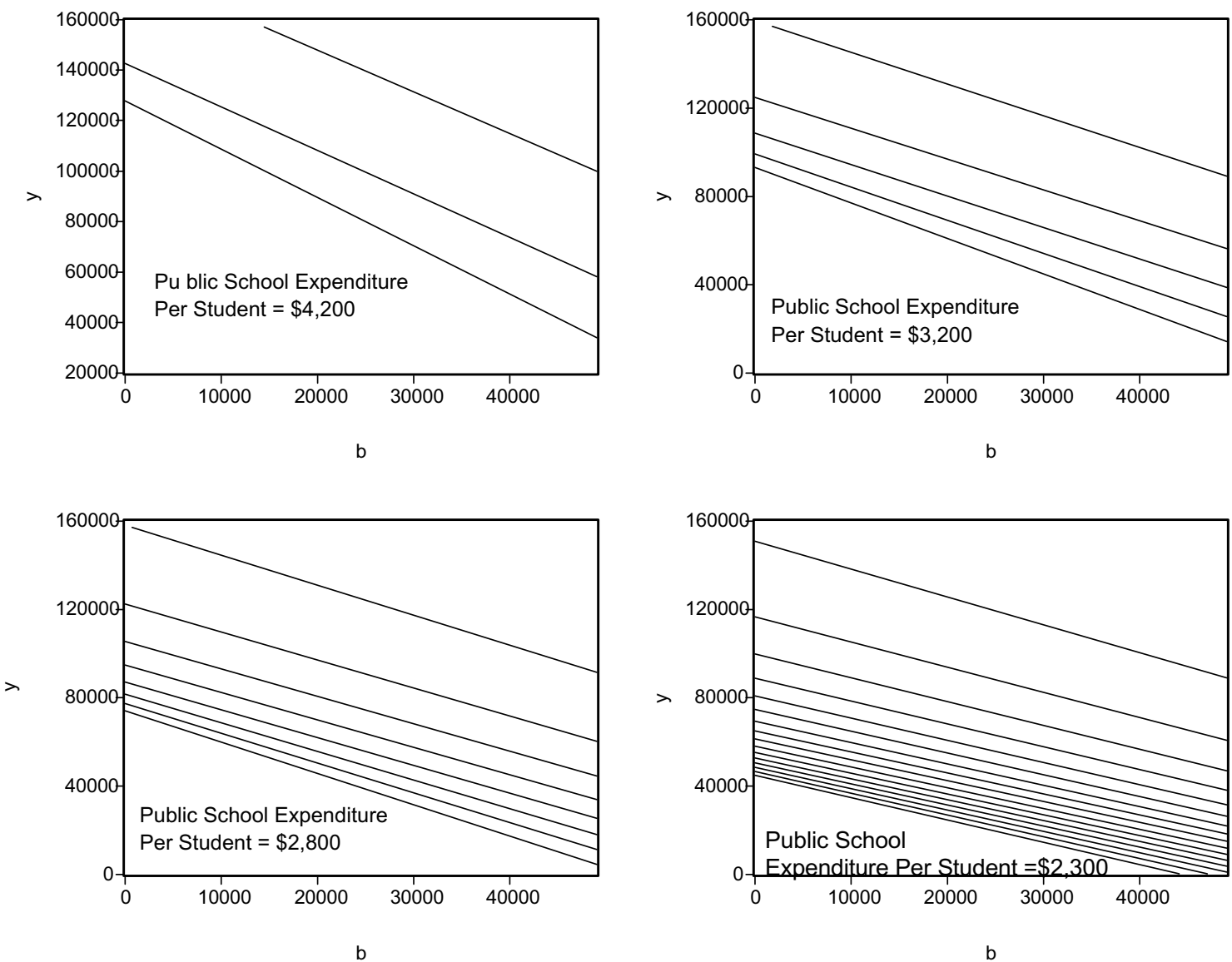
FIGURE 2

IMPLIED BOUNDARY LOCI FROM CONDITIONAL LOGIT MODELS, TABLE 2

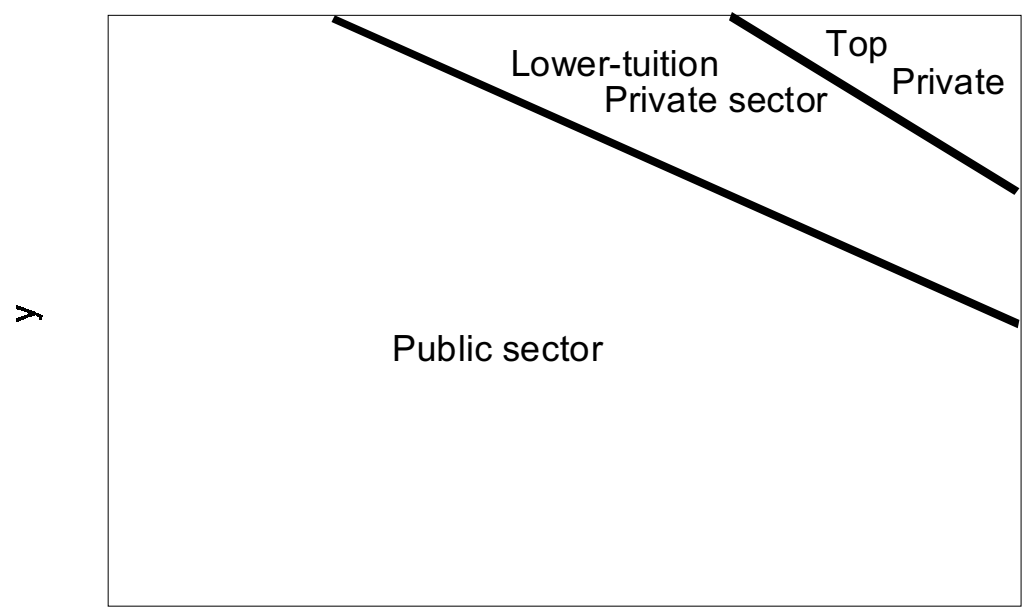

b 
FIGURE 3

ATTENDANCE IN PUBLIC SCHOOLS AS A FUNCTION OF PUBLIC SCHOOL EXPENDITURE PER STUDENT

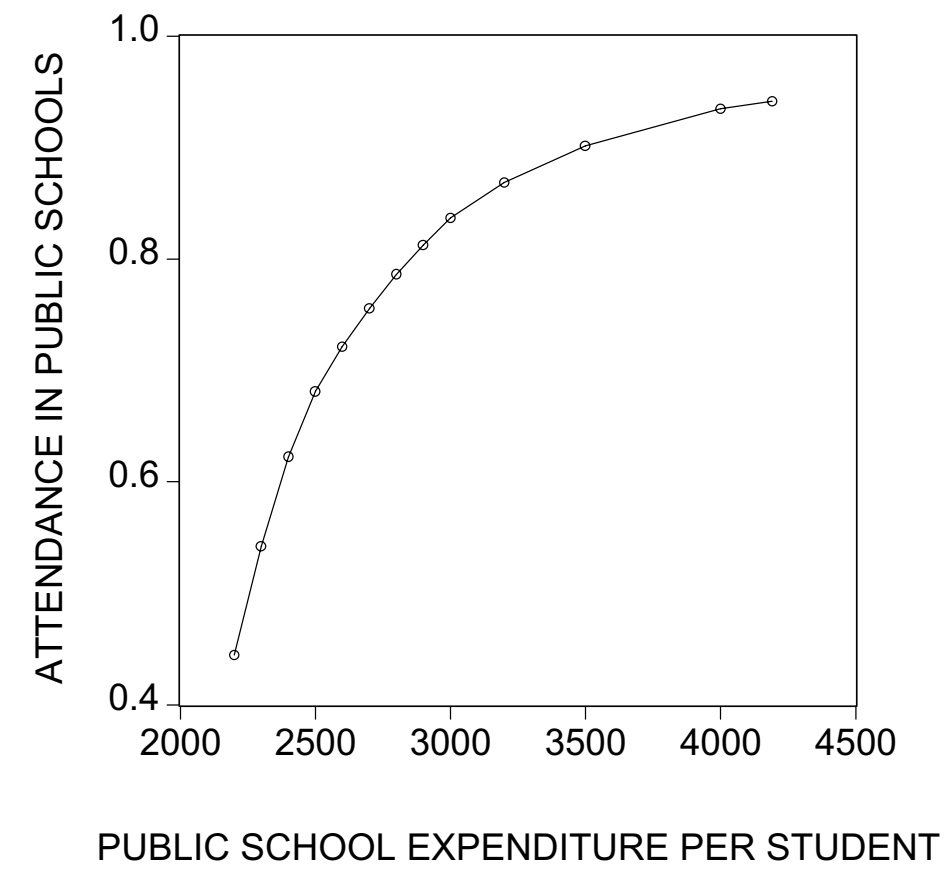


FIGURE 4

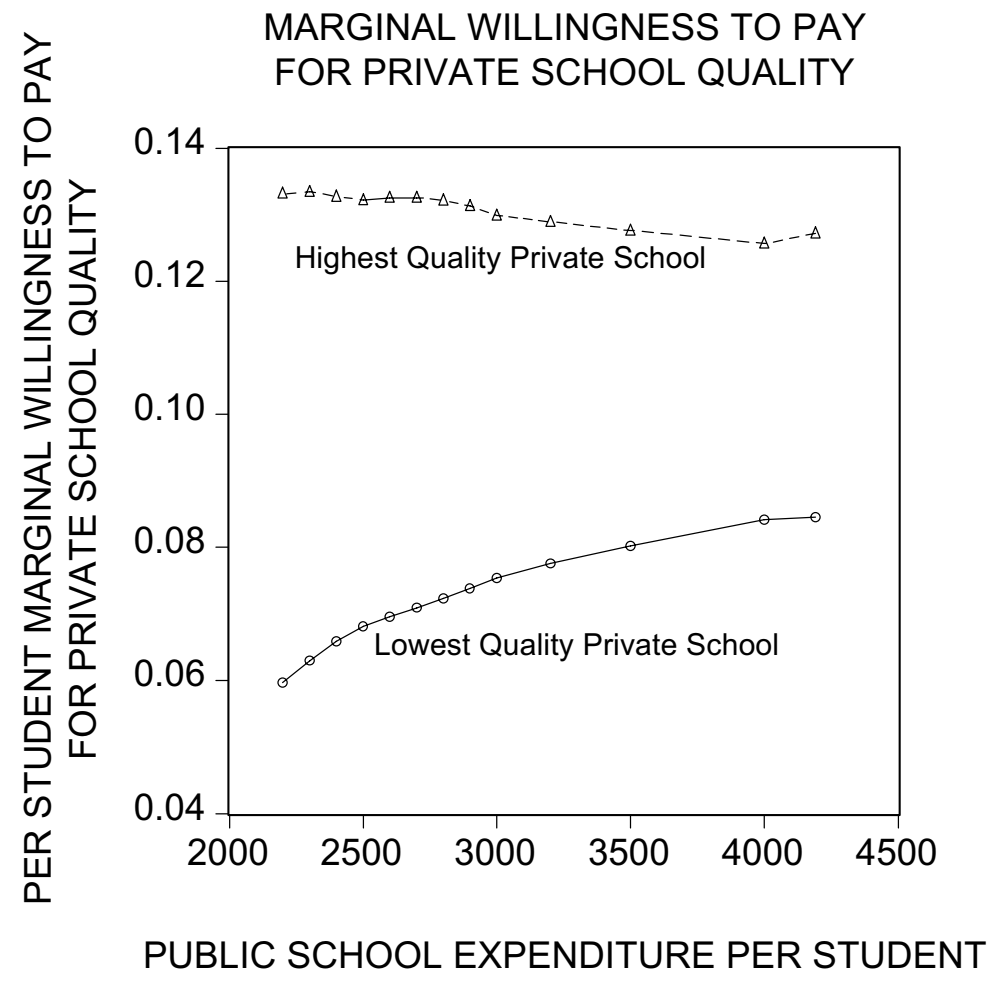


Footnotes.

1. The most closely related theoretical research is by Caucutt (forthcoming) and Nechyba (1999, 2000). See also Arnott and Rowse (1987), Benabou (1996a,1996b), Conley and Wooders (1998), de Bartolome (1990), and Rothschilde and White (1995).

2. The computational model actually presumes $1 / 2$ school-age children per household, which is closer to the empirical average.

3. Without effecting the qualitative predictions of the model, the peer measure can be generalized to be the school's mean of an increasing function of student ability. If the latter function is concave, for example, this allows achievement gains from decreased variation in student ability in a school as might result due to curriculum honing.

4. Note that indifference curves in the $(p, q)$ plane become steeper as income rises. This "single crossing" interpretation is useful for demonstrating stratification properties of equilibrium.

5. This is as in the literature on competitive clubs (see Scotchmer(1994)).

6. Voting equilibrium is also invariant to these alternative timing specifications as discussed below.

7. The distribution is actually truncated at large values of $y_{x}$ and $b_{x}$.

8. Summers and Wolfe (1977) and Zimmer and Toma (1999) find that disadvantaged students benefit more from good peers, while Henderson, Mieszkowski, and Sauvageau (1978) conclude that the effect is similar across ability levels. See Black (1999) for evidence of peer effects using housing price data.

9. $U_{i}^{e}(b, y)$ will also be seen to equal the equilibrium utility of type $(b, y)$.

10. Result 3(b) holds under somewhat more restrictive theoretical conditions than Results 1,2 , and 3(a). Result 3(b) also holds consistently in our computations, and we take it to be a robust prediction of our model.

11. The public school must be of lower quality than any private school simply because (at least some) students pay to attend any private school.

12. For Result 5(a), it is sufficient though not necessary that any of the following hold: (i) b and $y$ are stochastically independent and $\gamma<1$. (ii) Mean household income of student bodies rises with private school quality and $\mathrm{k}^{*}$ is small. (iii) The $\eta$ 's ascend weakly in private schools (i.e., $\eta_{n} \geq \eta_{n-1} \geq \ldots \geq \eta_{1}$ ). Like Result 3(b), we find 5(a) holds consistently in our computations and take it to be a robust prediction of our model.

13. We noted in Section 2 that the voting equilibrium is consistent with two specifications of the timing of choices. If schooling choices precede voting, then a household's preference mapping over tax and expenditure choices does not allow school switching. If voting and school choice take place simultaneously, then the household's preference mapping must account for own variation in school choice with the tax-expenditure combination. In either case, using (1), a single-crossing argument can be used to establish existence of voting equilibrium (see Epple and Romano (1996) and Gans 
and Smart (1996)). Further, voting equilibrium is the same in the two cases.

14. With more than two schools, the conditional distributions of ability in a school are quite complex.

15. In addition, we note that the empirical evidence that school sector per se influences student academic achievement, after correcting for selection, is weak, with the exception of low-income, inner-city minorities. See Figlio and Stone (1999).

16. The data support this theoretical result. Within a metropolitan area, private school tuitions are positively related to teacher salaries and negatively related to class sizes. We do not have information on private school expenditures.

17. We use the estimated parameters from the first set of logit results to predict public-private selection, and then, for the set of students predicted to attend private schools (i.e., the probability exceeds .5), we use the second set of logit results to predict within-private-sector selection. In essence, for this illustration, we sequentially place students in most-likely sectors of enrollment in the same manner as a multinomial logit model's predicted probabilities of sector selection would do simultaneously. In each step, the parameters used come from the conditional logit results that condition on metropolitan area of residence, but the pictures look quite similar were we to use other sets of results instead.

18. In the theoretical model a boundary locus is a locus of indifference between two adjacent schools in the quality hierarchy under equilibrium pricing. The corresponding locus in the statistical model is that locus along which the statistical model predicts the highest occurrence of indifference in a neighborhood. This is the locus where the predicted probability of choice between the two alternatives is .5 assuming the error term is zero.

19. These relationships, while presented separately, are estimated from the same regression.

20. Absent ability-related peer effects, but assuming demand for quality rises with ability, schools would price discriminate against higher ability as competition permits. Schools in the middle of the quality hierarchy would have limited power to engage in such discrimination. The top school faces less competition, i.e., none from "above" and so could charge higher-ability types more.

21. Equation (5) and Result 2(a) imply that discounting to ability declines as $\eta$ decreases for students at or near the margin of switching schools. We have found computationally that even a small number of private schools provides sufficient competition to place nearly all private-school students at this margin.

22. At the same time, private schools get larger as competition intensifies with entry of private schools. This is because their power to price discriminate over different income types declines as cheaper substitutes become available to students, making the relevant average revenue curves flatter. So, for example, the top school's boundary locus shifts down, while also becoming flatter (for the reasons discussed in the text).

23. If we assume that $\alpha_{1}=0$, wefind that the values of the numerators of these expressions are significant at the ten percent level for over eighty percent of the observations. 
24. We have also experimented with instrumenting for local public school expenditures using court-ordered school finance reforms, as well as the interaction between court-ordered school finance reforms and local median income, as instruments. While the conditional logit model is inconsistent with instrumental variables regression, one can still estimate an instrumental variables fixed-effects linear probability model. These results, available on request from the authors, are also supportive of the results described above.

25. We calculate this relationship by estimating a cross-sectional linear equation between average tuition (calculated using the aforementioned Dun and Bradstreet private school tuition data) and per pupil expenditures (generated from the Common Core of Data as mentioned above). We include no other control variables in this model so there are no further point estimates to report.

26. Note that the ability-income relationship remains negative in each case for reasonable values of public expenditure (e.g., $\$ 4,000)$. 